\author{
ALLA KOZHINOWA \\ ORCID: 0000-0002-5498-7037 \\ Белорусский государственный университет \\ WANG WENJUAN \\ ORCID: 0000-0001-9974-519X \\ Белорусский государственный университет
}

\title{
Формирование и развитие концепта «молодежь» в истории русского и китайского языков
}

Концепт мыслится ядерным понятием парадигмы когнитивной лингвистики, где под ним в наиболее общем смысле понимается «инвариант различных явлений, преломленных в языке» (Лукин 1993: 63). Свое современное содержание этот термин приобрел в когнитивно-лингвистических исследованиях конца XX-начала XXI вв. В этом контексте он определяется как явление, отличное от значения и от понятия — как ключевой термин культуры (Арутюнова 1991: 3). При рассмотрении концепта как отдельного явления ему отводится особое место в структуре человеческого сознания и когнитивной деятельности. При этом происходит дифференциация терминов «концепт» и «понятие»:

Основа понятия - логическая, рациональная и в том случае, если оно научное, и в том случае, если оно наивное... Основа концепта - сублогическая. Содержание концепта включает в себя содержание наивного понятия, но не исчерпывается им, поскольку охватывает все множество коннотативных элементов имени, проявляющихся в его сочетаемости (Чернейко, Долинский 1996: 21).

Предполагается, что концепты, связанные непосредственно с преломлением в сознании человека реальности, могут составлять основу картины, образа или модели мира. В подобной модели «фиксируются общие представ- 
ления субъекта о действительности и его знания о конкретных (уникальных) фактах и событиях» (Баранов, Добровольский 1990: 456).

Концепт «молодежь» относится к чрезвычайно интересным объектам исследования хотя бы потому, что он явно выделяется на фоне остальных концептуальных образований, связанных с отражений в языковом образе мира представлений о возрастном делении человечества. Здесь следует упомянуть, в частности, тот факт, что представляющая его лексема молодежь в русском языке является единственным собирательным возрастным наименованием. Ни для обозначения лиц детского возраста, ни для именования зрелых человеческих особей подобного не наблюдается. В один ряд с названной лексемой невозможно поставить и лексему старичье, оцениваемую в современном толковом словаре русского языка как пренебрежительное наименование (Новейший большой толковый словарь русского языка 2008: 1261), что, безусловно, ощущается всеми русскоязычными говорящими.

Сама лексема молодежь появляется в русском языке достаточно поздно. Первое ее употребление фиксируется Словарем русского языка XI-XVII вв. в 1697 г. (Словарь русского языка XI-XVII вв. 1982: 248), но еще Словарь Академии Российской (Словарь Академии Российской 1793: 166) квалифицирует это слово как просторечное. Однако уже в Словаре церковно-славянского и русского языка помета исчезает (Словарь иерковно-славянского и русского языка 1847: 319), следовательно, слово воспринимается как стилистически нейтральное. Возможно также некоторое сужение семантики по сравнению с современным значением: В. Даль указывает, что молодежь - это 'молодые люди обоего пола, но более мужчины' (Даль 2003: 332).

Несмотря на то, что китайский язык относится к совершенно иному языковому типу, нежели русский, с иным представлением о множественности и собирательности, в нем можно обнаружить сходные исторические основы формирования концепта. Так, русской лексеме молодежь в нем соответствуют именования 年轻人, 年青人 и 青年人, имеющие значение 'молодежь, молодые люди', а также 青年 со значениями '1) молодость, возрастной период приблизительно с 15-16 до 30 лет; 2) молодежь, человек в период приблизительно с 15-16 до 30 лет’ (现代汉语词典 2015: 1055).

Из перечисленных номинаций наиболее употребительным является 青 年. Ее ранние употребления демонстрируют реализацию смыслов 'молодость' (亮青年立志, 白首奋身, 敢不益励初心, 期在重温旧业 (В молодости (青年) я стремлюсь изо всех сил достичь определенной цели, никогда не забываю первоначального намерения, надеюсь начать заново) [陈亮 (Чэнь Лян (1143-1194))] $\left(\mathrm{BCC}^{1}\right)$ ) и 'молодой' (及至进来一看, 却是位青年公子: 头上戴着束发嵌宝紫金冠, 齐眉勒着二龙戏珠金抹额 $(O H$ вотел, это был

1 Здесь и далее: Корпус китайского языка Пекинского лингвистического университета (http://bcc.blcu.edu.cn/index.php). 
молодой (青年) барин, на голове у него обруч из червонного золота с драгоценными камнями, собравший волосы в пучок, на лбу над бровями налобник с узором двух драконов, играющих с жемчужиной [红楼梦 (Цао Сюэцинь, Сон в красном тереме), 1971 (CNCORPUS $^{2}$ ). Эти, а также другие примеры из языковых корпусов показывают, что лексема 青年в древней китайской литературе обозначала, скорее, возрастной период и чаще использовалась для описания возраста отдельного индивида - интеллигента и аристократа, но не служила для номинации отдельной социальной группы.

Процесс формирования рассматриваемого концепта растягивается в китайском языке на несколько веков. Китайский исследователь У Дуань отмечает, что номинация 青年 впервые появляется в стихотворении 寄张源 (К Чжану Юаню) поэта Моу Жун династии Тан (618-907) (吴端 2009: 1318). Далее автор обращает внимание на то, что эпохи Вэй, Цзинь, Северных и Южных династий (общий термин для исторического периода 220-589 гг.) являются важным этапом теоретизации и систематизации даосизма. Именно в этот период в даосизме возвеличивалось понятие, явление и цвет, который представляет первый иероглиф приведенной номинации 青 'зеленый или синий'. Считалось, что это не только представление благородного цвета, но и еще, что более важно, обозначение кипучей жизненной энергии. Культ поклонения зеленому цвету символизирует понимание сути жизни и стремление к жизненной силе, этот цвет является знаком долголетия и концепции продолжительности жизни. На этой основе возникло древнее китайское наименование 青年, обозначающее молодость (а позже и молодежь), которое дословно переводится как 'синий или зеленый год'. Оно устанавливает соответствие между циклами жизни человека и природы, так как через наблюдение природы познается закон жизни человека. Это является важной составляющей концепта «молодежь» в языке Древнего Китая.

Концепт «молодежь» в русском языке также формируется на базе осмысления природных реалий, однако в этом случае на первый план выходят не философские основания, а бытовые параллели. По данным Словаря русского языка XI-XVII в., лексема молодежь, помимо представления молодых людей, использовалась также для обозначения молодых животных, птиц и молодого леса, причем фиксация этих лексико-семантических вариантов также приходится на конец XVI-начало XVII вв. (Словарь русского языка XI-XVII вв. 1982: 248). Образование же с иной финалью (молодежъ) обозначало молодых пчел (там же).

Этот же семантический переход «молодые животные, птицы, деревья > молодые люди» представлен и в случае лексемы молодняк, которая впервые фиксируется в словаре В. Даля в значении 'молодая лесная поросль' (Даль

2 Здесь и далее: Корпус китайского языка государственного комитета языков (http:// www.cncorpus.org). 
$2003,332)$, а в новейшем словаре русского языка, помимо указания на значение 'молодые люди', снабжается также толкованиями 'молодые животные и птицы' и 'молодой лес' (Новейший большой толковый словарь русского языка 2008: 552). Следует отметить, что прозрачная внутренняя форма обусловливает и синтагматическое поведение рассматриваемой лексемы в ближайшем контексте могут встречаться единицы, подтверждающие ее связь с обозначением представителей растительного и животного мира: $3 a$ те минут сорок, что он здесь сидел, несколько стаек молодняка успели огомонить и расиветить молодым щебетом комнату, за одним из столиков затеяли даже громогласный спор, кто-то вылграл, побежденная отказывалась платить проигрыш почелуем... [Д. Рубина, Белая голубка Кордовы, 2008-2009] (НКРЯ $\left.{ }^{3}\right)$.

Интересным в связи с этим представляется развитие семантики слова молодь, для которого словарь приводит только значение 'молодые, недавно появившиеся на свет животные, растения (преимущественно о рыбе)' (Новейший большой толковый словарь русского языка 2008, с. 553), однако в НКРЯ можно встретить современные примеры, где этой лексемой именуются молодые люди: Вот туда-то, на картошку, которой было еще достаточно в деревне, и отправляли нас — молодь - по мере того как мыл, появившись на свет Божий, взрослели и уступали место у материнской груди следуюшему младениу [Г. Жженов, Прожитое, 2002]. Это указывает на то, что данный семантический переход представляется живым языковым явлением.

Получается, таким образом, что в основе формирования концепта «молодежь» в русском и китайском языках лежит хотя и различный, но все-таки натуроморфизм, когда фрагмент человеческого социума номинируется на основе параллелей с природными состояниями. Однако различия представляются достаточно весомыми, и связаны они не только с бытовым в одном случае и с философским - в другом представлениями. Если для китайского языка, как уже говорилось, понимание молодежи формируется на основе представления о жизненной силе, то для псл. *moldz, лежащего в основе русских номинаций, «восстанавливается перв. значение 'мягкий, нежный, слабый’» (Этимологический словарь славянских языков 1992: 179). Возможно, с этим в определенном смысле коррелирует внутренняя форма еще одной китайской номинации (年轻人), которую составляют части 年 ‘год’, 轻 ‘легкий' и 人 ‘человек', поскольку смысл ‘легкий’ можно также представить как 'незначительный, небольшой, слабый'.

Но если для китайца, исповедовавшего даосизм в древнем Китае, молодость была самым прекрасным периодом жизни человека, то для жителя Древней Руси этот период, по-видимому, являлся достаточно ущербным

3 Здесь и далее: Национальный корпус русского языка (ruscorpora.ru). 
- косвенным подтверждением этому являются то, что прилагательные младой//молодой (Словарь русского языка XI-XVII вв. 1982: 186-187, 249) имеют в составе своей семантики компоненты 'неопытный, незрелый', 'изнеженный', 'низший по званию, общественному положению', 'незрелый, пресный', а в словах-композитах первый корень млад-//молод- вносит в семантику различного рода пейоративные смыслы: младоотечныл - это 'не принадлежащий к старинному, знатному роду', то есть безродный, младотьльныли - 'изнеженный, неприспособленный', младо(молодо)умныл 'имеющий незрелый или слабый, недалекий ум'.

Хотя предпосылки появления наименований молодежи появляются еще в языке Древнего Китая, современное понятие «молодежь» формируется в китайском языке приблизительно тогда же, когда и в русском - в XVII в., о чем свидетельствуют примеры из корпусов текстов: 尽有贫苦的书生向 富贵人家求婚，便笑他阴沟洞里思量天鹅肉吃。忽然青年高第，然后大家 懊悔起来, 不怨怅自己没有眼睛, 便嗟叹女儿无福消受 (Бедные интеллигенты сваталась к дочерям состоятельных людей, которые над ним смеялись, говоря, что они живут в сточной канаве, а хотят поесть лебяжьего мяса. И вот неожиданно молодые люди (молодежь (青年)) успешно сдали государственный экзамен (Кэизюй) по отбору долэностных лиц. После этого эти (состоятельные) люди стали раскаиваться, мол, где были их глаза раньше, и вздыхали, что их дочери упустили такое счастье пользоваться благами жизни) [初刻拍案惊奇 Лин Мэнчу, (Поразительное. Первая часть), 1627]; 王夫人有言, 不令年轻人受礼, 恐折了福寿, 故此皆不磕头 (Госпожа по фамилии Ван сказала, что молодежи (年轻人) не следует почтительно кланяться ей, ибо она боится, что это приведет ее к недолголетию и несчастью, поэтому никто не клал ей земныле поклонь) [红楼梦 (Цао Сюэцинь, Сон в красном тереме), 1791] (CNCORPUS).

Это объясняется тем, что современное понятие «молодежь» в русском и китайском языках появилось благодаря развитию образования и промышленного производства в новое время. Реализуя в середине XVIII в. промышленную революцию, общество стало требовать от своих членов новые рабочие навыки. Соответственно, увеличился срок обучения человека, а момент вступления во взрослую жизнь отодвинулся. Все это способствовало формированию рассматриваемого понятия, используемого для наименования группы лиц, вышедших из детского возраста и готовящихся к самостоятельной жизни, но не занявших в ней соответствующую позицию. Таким образом, понятие «молодежь» является продуктом социальной цивилизации (中国独 生子女教育百科 1999).

Далее, развитию концепта «молодежь» в китайском языке способствовали несколько важных общественных явлений: появление в 1915 г. китайского издания «Журнал молодежи», а также движение за новую культуру, развернувшееся 4 мая 1919 г. Молодежь, будучи главной силой социального 
развития страны, активно участвовала во всех жизненно важных процессах и оказывала всестороннее влияние на экономическое, политическое и культурное развитие общества. Появляются новые номинации 年青人 и 青年人, в которых рассмотренное выше сочетание смыслов дополняется иероглифом 人 ‘человек': 如今的年青人开通多啦, 我娶你三嫂子的时候, 半年多 的工夫，同着人还不敢说话呢 (Сегодняиняя молодежь (年青人) более открыттая, чем когда я женился на твоей третьей по стариинству сестре, полгода с лишним мы стеснялись заговорить в присутствии других [三侠 剑 (Чжан Цзэсинь, Три рыцุаря и фехтовальщчика на мечах) 1920] (CСL ${ }^{4}$ ); 于是徐兰的名声传遍浙江一带，有钱有势的青年人无不赶到徐兰这里来 (Так Сюй Лан стала очень известна во всей провинции Чжээзян, и богатье, влиятельные молодые люди (молодежь) (青年人) приехали кней [古今情海 (Цао Сюцзюнь, О древней и современной любви), 1922] (CCL).

Также и в русском языке новые номинации в рамках концепта «молодежь» появляются после Великой Октябрьской революции. Именно тогда возникает переносное значение, связанное с обозначением молодых людей, у слова молодняк, ср.: Багровые зори сочатся ядными каплями в неутомную кровь людского молодняка [В. Ветров, Кедровый дух, 1920-1929]) (НКРЯ), его также фиксирует Толковый словарь русского языка под ред. Д. Н. Ушакова (Толковылй словарь русского языка, 1938: 248). Лексема молодь в значении 'молодежь' впервые появляется в Национальном корпусе русского языка в 30-х гг. (Не знаю что, может быть, вращение их земли, сделало людей извращёнными, даже в войнах: дурачьё, они швыряют в смерть самое смертенепригодное, свою молодь [С. Д. Кржижановский, Мост через Стикс, 1931] (НКРЯ), хотя, как уже говорилось выше, словари до сих пор это значение не отражают.

Представления о природе, которые послужили основой формирования концепта, не актуальны для современной концептуальной семантики. Представители различных наук предлагают различные характеристики молодежной группы, как правило, начиная с очерчивания характерного для нее возрастного диапазона. Так, Российская сочииологическая эничиклопедия определяет его в границах 16-30 лет (Российская социологическая энцииклопедия 1998: 297), а академическая Малая медицинская эничиклопедия вообще не выделяет подобный период, распределяя очерченные социологами года между юношеским возрастом (16-21 год) и первым периодом зрелости (20-35 лет) (Малая медицинская энциклопедия 1991: 358). В китайских изданиях также не наблюдается единодушия: так, Словарь антропологии определяет возраст молодежи от 16-17 до 23-24 лет (人类学辞典1990), а, согласно Большому словарю гигиены, это понятие применимо к молодым людям в возрасте от 18

4 Здесь и далее: Корпус китайского языка центра исследования китайского языкознания Пекинского университета (http://ccl.pku.edu.cn). 
до 25 лет (卫生学大辞典 2000); по критериям Государственного статистического управления КНР, молодежь - это люди в возрасте 15-34 лет; по критериям Всекитайской Молодежной Федерации - 18-40 лет; по долгосрочному плану развития молодежи (2016-2025 г.), утвержденному Центральным комитетом Коммунистической партии Китая и Госсоветом КНР - 14-35 лет (Из известий Агентства Синьхуа, Пекин, 13 апреля 2017 г.). В соответствии с критериями Всемирной организации здравоохранения ООН по классификации возраста человека, молодежью считаются люди в возрасте до 44 лет (данные 2013 г.).

Однако, как известно, языковая картина мира может отличаться от научной, поэтому для характеристики современного концепта молодежь в русском и китайском языках необходимо определить диапазон возраста на основании словарных данных, а также текстовой фреквенции составляющих его лексем.

Поскольку слово молодежь в русском языке - собирательное существительное, то и искомый возрастной диапазон в текстах НКРЯ представлен именно как период, причем конкретный возраст выступает в качестве точки отсчета - как правило, конечной (Однако за ограничения выступает и молодежь: 58\% россиян в возрасте до 23 лет поддержали инициативу правительства [Д. Пузырев, «Сухому закону» дали добро, 2010] или Так развеивается другой стереотип: будто бы на улищы и площзади «высыпала молодежь» — людей моложе 25 лет там было около одной пятой [Б. Дубин, Сдвиг, 2012]), реже начальной (Этой настоящчей честности молодежи не хватает, молодежь уже с 14-ти лет живет, всё планируя и зная [Д. Климов, Цой не дает нам дремать, 2015]).

Именно 14-летие выступает в качестве нижней границы рассматриваемого периода, верхняя же граница приходится на возраст 30 лет: $B$ странах с более или менее устойчивой социальной структурой население достигает «пика» успеха в 40-50 лет, у нас же наиболее успешной считает себя молодежь до 30 лет, 50-летние в своем большинстве оценивают себя как соииальныле аутсайдеры [Д. Карасев Говорит и показывает народ, 2003] (НКРЯ). Такой диапазон, представленный в текстах, отчасти совпадает с официально признаваемым, ср. также: Региональные законы одних субъектов федерации причисляют к молодежни лии 14-30 лет, других, например Москвы, 一 от 14 до 25 лет, а в некоторых случаях до 27 лет, Все возрасту покорны [Б. Руденко, 2006]. При этом пик употреблений лексемы молодежь приходится на обозначение возраста 18-25 лет. Возраст же, заметно выходящий за эти временные рамки, может быть представлен только в иронически-оценочном контексте, на что указывают кавычки, сопровождающие рассматриваемую лексему: Мне «как молодежи» было тогда неполных шесть лет [Н. Мордюкова, Казачка, 2005] или К большому сожалению, я не застала в живых ста- 
рожилов, да и «молодежи» было уже по 70-80 лет [Н. Рыбакова, Овиьлнские страдания: о сохранности традииии, 2003] (НКРЯ).

B CNCORPUS примеры, содержащие точное указание на возраст, охватывают возрастной период от 14 до 44 года. Как видно, этот диапазон охватывает все возрастные вехи, предлагаемые различными, в том числе всемирными, организациями, ср. 但周围尽是一些带笑的, 蚌然的脸, 只 有在他的后面, 隔着两三个人, 站着一个二十多岁的青年 (Но кругом лииа с глупой улыбкой, в отличие от стоящейза его спиноймолодежи 20 с лишним лет) [巴金 (Ба Цзинь, Трагедия ночи), 1948]; 电子显微镜还只是二十几岁的 青年 (Электронный микроскоп - это только лишь «молодежь» старше двадиати лет) [Ван Хунвэй, Электронная зеркальная комната].

В русском языке слово молодежь не образует устойчивых сочетаний. Современный же китайский язык демонстрирует более богатое наполнение соответствующего концепта, возможность при помощи специальных номинаций представить сложные представления о структуре данной возрастной группы. Так, как было показано выше, трудно определить, когда человек из состояния молодости переходит в зрелый возраст (ср. приведенную выше медицинскую классификацию). Подобный переход закладывается в структуру китайского концепта «молодежь», поскольку в языке существует номинация 中青年, где к уже рассматриваемым компонентам добавляется компонент 中 'средина, средний', в результате чего вся номинация приобретает значение 'люди средних лет и молодежь' (现代汉语大词典 2009).

В китайском языке можно определить возраст референта более точно, используя специальную номинацию 小青年, досл. 'маленькая молодежь', 'молодежь в возрасте около 20 лет' (现代汉语规范词典 2014: 1445; 沈孟璎 2009), в состав которой входит лексема 小 'маленький; мелкий; небольшой по величине, объёму, размерам и т. п.; младший человек по возрасту’. Рассматриваемая лексема входит также в состав номинации 小年轻 с тем же значением (现代汉语规范词典 2014: 1445).

Представлена также номинация 大青年, досл. 'большая молодежь', которая обозначает молодежь в возрасте около 30 лет, еще не вступившую в брак (沈孟顼 2009), в которой указанные выше составляющие дополняются еще одним компонентом - 大 'превышающий другие предметы по объему, площади, количеству, интенсивности и другим аспектам; пожилой человек, человек старшего возраста' (现代汉语词典 2015: 238). Второе значение этой лексемы ('пожилой человек') дает возможность указанной номинации принимать участие в формировании выражения 大龄青年, досл. 'старая молодежь', обозначающего молодых людей, возраст которых значительно превышает оптимальный, подходящий, брачный возраст, не вступившую в брак и слишком старую для вступления в брак (现代汉语词典 2015: 242).

Как представляется, подобное деление связано с формированием еще в составе конфуцианской этики, возрождающейся в последнее время, уваже- 
ния к старшим по возрасту и положению. На появление же в структуре значения соответствующих номинаций, а следовательно, и в смысловой структуре самого концепта, компонента 'брачный возраст' влияет демографическая и социальная ситуация. По данным шестой общегосударственной переписи населения от 28-го апреля 2011 г., в Китае мужское население составляет 51,27\%, а женское - 48,73\% (赵煜程 2011: 37-53). В связи с этим мужчины как представители более многочисленной группы испытывают трудности при создании семьи, и прежде всего, это мужчины, относящиеся к низшим слоям общества. Но трудности испытывают и успешные женщины с высшим образованием, поскольку они не могут подобрать себе достойную пару.

Возможно, в связи с этим представление концепта «молодежь» в китайском языке предполагает не только возрастную, но и половую дифференциацию. Она реализуется за счет добавления к номинации 青年 компонента 男 'мужской, мужчина', в результате чего образуется номинативная единица 男 青年 ‘молодежь мужского пола'; соответственно, если к данной номинации добавить компонент 女 ‘женский, женщина', то образуется название 女青年 'молодежь женского пола'.

Таким образом, в формировании концепта «молодежь» в русском и китайском языках можно найти и различие, и сходство, причем если первое обнаруживается на структурном уровне (различная понятийная детализация - возможность выражения дополнительных смыслов в рамках китайского концепта), то второе проявляется на генеративном уровне (сходные когнитивные основания формирования концептов), а также на функциональном, поскольку современное понятие «молодежь» в обоих языках сформировалось приблизительно в одно и то же время, также практически одновременно произошло увеличение количества лексем, представляющих данный концепт.

\section{Библиография}

Арутюнова Н. Д. (1991), Введение, [в:] Культурные концепты, Москва, с. 3-6.

Баранов А. Н., Добровольский Д. О. (1990), Постулатьл когнитивной семантики, «Известия АН России, Серия литературы и языка», т. 56, № 1.

Даль В. И. (2003), Толковый словарь живого великорусского языка, т. 2, Москва (Репринт. воспр.

2-го изд. 1880-1882 гг.).

Лукин В. А. (1993), Концепт истины и слово истина в русском языке (Опьт концептуального анализа рачионального и иррачионального в языке), «Вопросы языкознания», № 4, c. $63-86$.

Малая медищинская энщииклопедия (1991), ред. В. И. Покровский, т. 1, Москва.

Новейший большой толковый словарь русского языка (2008), гл. ред. С. А. Кузнецов, СанктПетербург.

Российская соииологическая энщиклопедия (1998), ред. Г. В. Осипов, Москва. 
Словарь Академии Российской (1793), сост. Д. И. Фонвизин [и др.], ч. 4, Санкт-Петербург.

Словарь русского языка XI-XVII вв. (1982), отв. ред. Р. И. Аванесов, вып. 9, Москва.

Словарь ичерковно-славянского и русского языка (1847), сост. Вторым Отд-нием Императ. Акад. наук, т. 2, Санкт-Петербург.

Толковый словарь русского языка (1938), гл. ред. Д. Н. Ушаков, т. 2, Москва.

Чернейко Л. О., Долинский В. А. (1996), Имя СУДЬБА как объект кониептуального и ассочиативного анализа, «Вестник Московского университета», сер. 9, Филология, № 6, c. $20-41$.

Этимологический словарь славянских языков: праславянский лексический фонд (1992), ред. О. Н. Трубачев, вып. 19, Москва.

人 学辞典 $[\mathrm{M} / \mathrm{OL}](1990)$, 李金锤, 蒋宝德, 张承芬, 卢延禄, 辛绍盛等, 北京: 华艺出版社, http:// xuewen.cnki.net/read-R2009050290000224.html (дата доступа: 15.08.2017).

沈孟顼 (2009), 新中国60年新词新语词典 [M/OL], 四川成都: 四川出版集团・四川辞书出版 社, http://xuewen.cnki.net/readR2012111080005254.html (дата доступа: 26.08.2017).

吴端 (2009), 青年的虚像与实像一对中国的 “青年” 概念原创时期特征的探讨 $[J]$. 当代 青年研究，(7)，上海.

卫生学大辞典 [M/OL] (2000), 王翔朴, 王营通, 李玨声, 青岛: 青岛出版社, http://xuewen.cnki. net/read-R2006050460003228.html (дата доступа: 27.08.2017).

现代汉语词典 (2015), 中国社会科学院语言研究所词典编辑室. 现代汉语词典 [M]. 第6版. 北京: 商务印书馆.

现代汉语大词典 [M/OL] (2009), 阮智富, 郭忠新, 上海: 上海辞书出版社, http://xuewen.cnki. net/read-R2012111530003925.html (дата доступа: 25.08.2017)

现代汉语规范词典 (2014), 李行健, 第3版, 北京: 外语教学与研究出版社.

中国独生子女教育百科 [M/OL] (1999), 林崇德, 俞国良, 李辉, 浙江杭州: 浙江人民出版社, http://xuewen.cnki.net/readr2006062710001927.html (дата доступа: 26.08.2017).

赵煜程 (2011), 我国独生子女政策实施以来的出生性别比变化研究, 博士学位论文, 华中科技 大学, 武汉.

\section{Bibliografia}

Arutyunova N. D. (1991), Vvedeniye, [v:] Kul'turnyye kontsepty, Moskva, s. 3-6.

Baranov A. N., Dobrovol'skiy D.O. (1990), Postulaty kognitivnoy semantiki, [v:] «Izvestiya AN Rossii, seriya lit. i yazyka», t. 56, № 1, s. 11-21.

Chén Mèngyīng (2009), Xīn Zhōngguó 60 nián xīn cí xīn yǔ cídiăn [M/OL], Sìchuān Chéngdū: Sìchuān chūbăn jítuán. Sìchuān císhū chūbăn shè,, http://xuewen.cnki.net/readR2012111080005254. html (dostęp: 26.08.2017).

Cherneyko L. O., Dolinskiy V. A. (1996), Imya SUD'BA kak ob "yekt kontseptual'nogo i assotsiativnogo analiza, „Vestnik Moskovskogo universiteta”, ser. 9, Filologiya, № 6, s. 20-41.

Dal' V. I. (2003), Tolkovyy slovar' zhivogo velikorusskogo yazyka, t. 2, Moskva (Reprint. vospr. 2-go izd. 1880-1882 gg.).

Etimologicheskiy slovar' slavyanskikh yazykov: praslavyanskiy leksicheskiy fond (1992), red. O. N. Trubachev, vyp. 19, Moskva.

Lukin V. A. (1993), Kontsept istiny i slovo istina v russkom yazyke (Opyt kontseptual'nogo analiza ratsional'nogo i irratsional'nogo v yazyke), [v:] Voprosy yazykoznaniya, № 4, s. 63-86.

Malaya meditsinskaya entsiklopediya (1991), red. V. I. Pokrovskiy, t. 1, Moskva.

Noveyshiy bol'shoy tolkovyy slovar' russkogo yazyka (2008), gl. red. S. A. Kuznetsov, Sankt-Peterburg. 
Rénlèi xué cídiăn [M/OL] (1990), Lǐ Xīnshēng, Jiăng Băodé, Zhāng Chéngfēn, Lú Yánlù, Xīn Shàoshèng děng, Běijīng: Huá yì chūbăn shè, http://xuewen.cnki.net/read-R2009050290000224. html (dostęp: 15.08.2017).

Rossiyskaya sotsiologicheskaya entsiklopediya (1998), red. G. V. Osipov. Moskva.

Slovar' Akademii Rossiyskoy (1793), sost. D. I. Fonvizin [i dr.] ch. 4, Sankt-Peterburg.

Slovar' russkogo yazyka XI-XVII vv. (1982), otv. red. R. I. Avanesov, vyp. 9, Moskva.

Slovar' tserkovno-slavyanskogo i russkogo yazyka (1847), sost. Vtorym Otd-niyem Imperat. Akad. nauk, t. 2, Sankt-Peterburg.

Tolkovyy slovar' russkogo yazyka (1938), gl. red. D. N. Ushakov, t. 2, Moskva.

Wèishēng xué dà cídiăn [M/OL] (2000), Wáng Xiángpǔ, Wáng Yíngtōng, Lǐ Juéshēng, Qīngdăo: Qīngdǎo chūbăn shè, http://xuewen.cnki.net/read-R2006050460003228.html (dostęp: 27. 08.2017).

Wú duān (2009), Qīngnián de xūxiàng yǔ shíxiàng — dui zhōngguó de "qīngnián" gàiniàn yuánchuàng shiqi tèzhēng de tàntăo [J]. Dāngdài qīngnián yánjiū, (7), Shànghăi.

Xiàndài hànyǔ cídiăn (2015), Zhōngguó shèhuì kēxuéyuàn yǔyán yánjiū suǒ cídiăn biānjí shì. Xiàndài hànyŭ cídiăn $[\mathrm{M}]$. Dì 6 băn. Běijīng: Shāngwù yìn shūguăn.

Xiàndài hànyǔ dà cídiăn [M/OL] (2009), Ruăn Zhìfù, Guō Zhōngxīn, Shànghăi: Shànghăi císhū chūbăn shè, , http://xuewen.cnki.net/read-R2012111530003925.html (dostęp: 25.08.2017).

Xiàndài hànyǔ guîfàn cídiăn (2014), Lǐ Xíngjiàn, dì 3 băn, Běijīng: Wàiyǔ jiàoxué yǔ yánjiū chūbăn shè. Zhōngguó dúshēngzǐ nŭ jiàoyù bǎikē [M/OL] (1999), Lín Chóngdé, Yú Guóliáng, Lǐ Huī, Zhèjiāng Hángzhōu: Zhèjiāng rénmín chūbăn shè, http://xuewen.cnki.net/ readr2006062710001927.html (dostęp: 26.08.2017).

Zhào Yùchéng (2011), Wõguó dúshēngzǐ nü zhèngcè shíshī yùlái de chūshēng xìngbié bì biànhuà yánjiū, bóshì xuéwèi lùnwén, Huázhōng kējì dàxué, Wǔhàn.

\section{The concept of youth in the history of the Russian and Chinese languages}

\section{Summary}

The article examines the way the concept of youth was formed in historical and comparative perspective (based on the Russian and Chinese languages). Particular attention is paid to the means of expression of the given concept which holds a special place among mental constructions connected with the reflection of the idea of human age division in the language picture of the world based on the diametrically different cultures.

Keywords: cognitive linguistics, concept, history of language, Russian language, Chinese language 